\title{
Current Understanding and Future Prospects of Host Selection, Acceptance, Discrimination, and Regulation of Phorid Fly Parasitoids That Attack Ants
}

\author{
Kaitlyn A. Mathis ${ }^{1}$ and Stacy M. Philpott ${ }^{2}$ \\ ${ }^{1}$ Department of Environmental Science, Policy and Management, University of California, Berkeley, 137 Mulford Hall, Berkeley, \\ CA 94720, USA \\ ${ }^{2}$ Department of Environmental Sciences, The University of Toledo, 2801 W. Bancroft Street, MS 604, Toledo, OH 43606, USA
}

Correspondence should be addressed to Kaitlyn A. Mathis, kamathis@berkeley.edu

Received 29 August 2011; Accepted 3 November 2011

Academic Editor: Jean Paul Lachaud

Copyright ( $) 2012$ K. A. Mathis and S. M. Philpott. This is an open access article distributed under the Creative Commons Attribution License, which permits unrestricted use, distribution, and reproduction in any medium, provided the original work is properly cited.

\begin{abstract}
Phorid fly parasitoids (Diptera: Phoridae) have evolved a diverse array of cues used to successfully parasitize their ant hosts. Successful parasitism often involves (a) host habitat location, (b) host location, (c) host acceptance, (d) host discrimination, and (e) host regulation. In this paper we discuss our current understanding of how phorid flies use each of these steps to successfully parasitize ant hosts. We examine the wide variety of strategies and cues used by a multiple species of phorid flies within three separate genera that most commonly parasitize ants (Apocephalus, Pseudacteon, and Neodohrniphora) and discuss future directions within this field of study.
\end{abstract}

\section{Introduction}

Parasitoids have evolved effective and efficient methods of successful parasitism, many of which involve utilization of multimodal cues [1]. Many dipteran parasitoids in the family Phoridae use social insects as hosts due to the reliability of their intraspecific chemical communication signals that make for effective host selection cues [2-5]. Phorid fly adults parasitize ants by hovering over insect hosts and then diving down to insert an egg beneath the insect's exoskeleton $[3,6-$ 8]. Phorid flies have direct parasitic effects on ants (i.e., cause ant mortality) and also significantly change ant foraging behavior by limiting host resource acquisition behavior, modifying ant competitive hierarchies, and dampening ant effects on herbivores [9-14]. There are phorids that attack ants from at least 22 genera across 5 subfamilies. Likewise, more than 20 genera of phorids attack ant hosts [3]. With such taxonomic diversification in ant-phorid relationships, the types of cues used by phorids to locate, select, and successfully parasitize ant hosts are also quite diverse.
Successful parasitism requires a series of interactions between a parasitoid and its host. The process can be categorized into five general and sometimes overlapping steps: (a) host habitat location, (b) host location, (c) host acceptance, (d) host discrimination, and (e) host regulation [1].

For phorid parasitoids, host location involves the use of both habitat and host cues. Host habitat location is the use of environmental cues by the parasitoid to select areas to search for potential hosts. These cues may be directly related to the preferred environment of the host itself (e.g., volatiles from plants commonly used by hosts) or related to the parasitoid's general habitat preferences (light, temperature, and humidity conditions within a given area) [1]. The host location process also requires that a parasitoid use long-range cues to be directed to its' host. However, unlike host habitat location cues, these cues come directly from the host itself. Ants communicate interspecifically by using complex pheromones. These pheromones often act as host location cues for parasitoids as they can be both reliable (with volatile pheromones highly conserved within a species or 
genus) and detectable (ants, being eusocial, live in relatively high densities, and can produce large volumes of volatile pheromones) for the parasitoid [15]. Once a phorid parasitoid has located a potential host through long-range cues, the parasitoid requires host acceptance cues to trigger the parasitoid's oviposition behavior. Short-range cues such as movement, host size, and contact chemical cues have all been implicated in triggering phorid fly oviposition [7, 16-26].

In addition to the cues that are required for overall host selection, host discrimination cues, used by parasitoids to detect and reject potential hosts that have been previously parasitized, can be present. While these cues are not necessary for parasitism, they can increase the likelihood of offspring success [1]. Parasitoids can also increase the success rate of their offspring through host regulation, whereby parasitoids manipulate their hosts to promote the development of the next generation of parasitoids. Host regulation can involve altering the physiology of the host to facilitate growth and development of egg, larvae, or pupae of the parasitoid or altering host behavior to optimize nutrient intake or location within the external environment [27].

This paper focuses on our current understanding of the process by which phorid flies successfully parasitize ants. We examine the wide variety of strategies and cues used by multiple species of phorid flies within three separate genera (Apocephalus, Pseudacteon, and Neodohrniphora) to successfully parasitize ant hosts.

\section{Host Habitat Location}

Parasitoid habitat preference is a major factor that determines where parasitoids will search for hosts and therefore which hosts will be successfully parasitized. Some hosts are selected not because they have a greater degree of inherent suitability but because they happen to be in an environment where parasitoid abundance is greater or where parasitoids are better able to detect cues released by their hosts [1]. Light levels affect attack rates of several species of phorid flies. For example, Neodohrniphora tonhascai and Neodohrniphora elongate both attack Atta sexdens at significantly higher rates when in high-light-level laboratory conditions [28]. Field experiments with Pseudacteon litoralis and Pseudacteon tricuspis which attack ants in the Solenopsis saevissima complex show that these species prefer lower light levels (i.e., just after sunrise and before sunset) and higher light levels (midday sun), respectively [23]. Analogously, lab experiments with Pseudacteon curvatus show that the flies attack Solenopsis spp. ants on darker backgrounds at greater rates than ants on white or light backgrounds [29]. Pseudacteon spp. phorids that attack the Solenopsis saevissima also display habitat preferences based on environmental factors such as temperature, rainfall, photoperiod length, sugar availability, wind, humidity, and number of days with frosts [30-32].

Habitat complexity also affects phorid fly attack rates. Two species of phorid flies, Apocephalus sp. 8 and Apocephalus sp. 25 attack their host ants (Pheidole diversiphilosa and Pheidole bicarinata, resp.) at higher rates when leaf litter is less complex, most likely because the ants are able to take better refuge in more complex leaf litter [33]. Further,
Pseudacteon spp. attack rate on Azteca instabilis is higher in coffee plantations with lower shade tree canopy complexity although the exact set of habitat variables that create a preference for lower shade complexity remain unclear [34].

\section{Host Location}

The long-range cues used by phorid flies to hone in on potential hosts have been examined in several phorid-ant relationships. Some phorids travel at least $10-20 \mathrm{~m}$ to reach hosts and possibly up to $50 \mathrm{~m}$, thus host location cues are likely generally volatile compounds, which can be detected by parasitoids well beyond the visual range of their hosts [42]. While sound cues have the potential to be long range and have been documented in some non-phorid parasitoid-insect interactions, to date no phorid flies have been recorded to use sound as a cue in ant host location $[3,43]$. Paralleling the rich diversity of volatile ant pheromones, chemical host location cues used by phorid flies can vary widely in structure, glandular origin, and purpose in ant-phorid relationship (Table 1). Longrange cues for phorids derive from several glands (mandibular, pygidial, etc.) and represent a wide array of pheromone types (trail, alarm, etc.). Several specific examples of these cues for different ant-phorid relationships follow.

The first set of host location cues documented for phorids were in the "giant tropical ant" Paraponera clavata attacked by the phorid, Apocephalus paraponerae. Parasitism of $P$. clavata by A. paraponerae was first observed in 1958 by C. W. Rettenmeyer on Barro Colorado Island, Panama. Rettenmeyer originally suspected that the flies were attracted to audible stridulations made by $P$. clavata individuals when alarmed. However, field observations showed that $A$. paraponerae were attracted to mandibular gland extracts of $P$. clavata that contain alarm pheromone $[2,4]$. The two major products of the mandibular glands of P. clavata, 4-methyl-3heptanol and 4-methyl-3-heptanone (characterized in [35]), were tested individually and both attract $A$. paraponerae [4].

Another species of phorid fly that utilizes the alarm pheromones of its host is Pseudacteon brevicauda. Studies show that these phorid flies are attracted to mandibular gland extracts of their host, Myrmica rubra [36]. Within these glands are 3-octanone, 3-nonanone, and 3-octanol [37]. The two ketones were found to attract $P$. brevicauda from a distance [36]. While the alcohol, 3-octanol, did not attract flies from long distances, it was found to increase the "alertness" of the flies at a closer range, possibly indicating its synergistic role in host location or a possible role in host acceptance; however, further observations are needed to confirm the role of this compound [36].

Formic acid, a relatively common alarm and defense compound from the venom glands of ants, is the primary host location cue attracting Pseudacteon formicarum to the ants Lasius niger and Lasius emarginatus [38]. The use of formic acid is relatively common in ants, and previously $P$. formicarum was thought to be one of the only phorid flies with multiple hosts because these flies frequently arrive to areas where a wide variety of ants using formic acid are aggregated. However, it was recently discovered that $P$. formicarum is specific to ants in the genus Lasius, rather than all 
TABLE 1: Chemical host location cues used by phorid flies in search of ant hosts.

\begin{tabular}{|c|c|c|c|c|c|}
\hline Phorid species & Ant species & Cue & Source & Ant use & Ref. \\
\hline $\begin{array}{l}\text { Apocephalus } \\
\text { paraponerae }\end{array}$ & $\begin{array}{l}\text { Paraponera } \\
\text { clavata }\end{array}$ & $\begin{array}{l}\text { 4-Methyl-3-heptanol } \\
\text { and 4-methyl-3- } \\
\text { heptanone }\end{array}$ & $\begin{array}{l}\text { Mandibular } \\
\text { glands }\end{array}$ & $\begin{array}{c}\text { Alarm } \\
\text { pheromone }\end{array}$ & {$[2,4,35]$} \\
\hline $\begin{array}{l}\text { Pseudacteon } \\
\text { brevicauda }\end{array}$ & Myrmica rubra & $\begin{array}{l}\text { 3-Octanone and } \\
\text { 3-nonanone }\end{array}$ & $\begin{array}{l}\text { Mandibular } \\
\text { glands }\end{array}$ & $\begin{array}{c}\text { Alarm } \\
\text { pheromone }\end{array}$ & {$[36,37]$} \\
\hline $\begin{array}{l}\text { Pseudacteon } \\
\text { formicarum }\end{array}$ & $\begin{array}{c}\text { Lasius niger and } \\
\text { Lasius } \\
\text { emarginatus }\end{array}$ & Formic acid & Venom glands & $\begin{array}{l}\text { Alarm/defense } \\
\text { pheromone }\end{array}$ & {$[38]$} \\
\hline Pseudacteon spp. & Azteca instabilis & $\begin{array}{l}\text { 1-Acetyl-2- } \\
\text { methylcyclopentane }\end{array}$ & Pygidial Gland & $\begin{array}{c}\text { Alarm } \\
\text { pheromone }\end{array}$ & {$[17,39]$} \\
\hline $\begin{array}{l}\text { Pseudacteon } \\
\text { litoralis }\end{array}$ & $\begin{array}{l}\text { Solenopsis } \\
\text { saevissima } \\
\text { complex }\end{array}$ & Unknown & Unknown & $\begin{array}{l}\text { Unknown use at } \\
\text { disturbed } \\
\text { mounds }\end{array}$ & {$[20]$} \\
\hline $\begin{array}{l}\text { Pseudacteon } \\
\text { wasmanni }\end{array}$ & $\begin{array}{l}\text { Solenopsis } \\
\text { saevissima } \\
\text { complex }\end{array}$ & Unknown & Unknown & $\begin{array}{l}\text { Unknown use at } \\
\text { disturbed } \\
\text { mounds }\end{array}$ & {$[20]$} \\
\hline $\begin{array}{l}\text { Pseudacteon } \\
\text { obtusus }\end{array}$ & $\begin{array}{l}\text { Solenopsis } \\
\text { saevissima } \\
\text { complex }\end{array}$ & Unknown & Unknown & $\begin{array}{l}\text { Unknown use } \\
\text { on trails }\end{array}$ & {$[20]$} \\
\hline $\begin{array}{l}\text { Pseudacteon } \\
\text { borgmeieri }\end{array}$ & $\begin{array}{l}\text { Solenopsis } \\
\text { saevissima } \\
\text { complex }\end{array}$ & Unknown & Unknown & $\begin{array}{l}\text { Unknown use } \\
\text { on trails }\end{array}$ & {$[20]$} \\
\hline $\begin{array}{l}\text { Pseudacteon } \\
\text { nuicornis }\end{array}$ & $\begin{array}{l}\text { Solenopsis } \\
\text { saevissima } \\
\text { complex }\end{array}$ & Unknown & Unknown & $\begin{array}{l}\text { Unknown use } \\
\text { on trails }\end{array}$ & {$[20]$} \\
\hline $\begin{array}{l}\text { Pseudacteon } \\
\text { solenopsidis }\end{array}$ & $\begin{array}{l}\text { Solenopsis } \\
\text { saevissima } \\
\text { complex }\end{array}$ & Unknown & Unknown & $\begin{array}{l}\text { Unknown use } \\
\text { on trails }\end{array}$ & {$[20]$} \\
\hline $\begin{array}{l}\text { Pseudacteon } \\
\text { tricuspis }\end{array}$ & $\begin{array}{l}\text { Solenopsis } \\
\text { saevissima } \\
\text { complex }\end{array}$ & $\begin{array}{c}\text { 2-Ethyl-3, } \\
\text { 6-dimethylpyrazine }\end{array}$ & $\begin{array}{l}\text { Mandibular } \\
\text { glands }\end{array}$ & $\begin{array}{c}\text { Alarm } \\
\text { pheromone }\end{array}$ & {$[40,41]$} \\
\hline
\end{tabular}

ants that use formic acid, which indicates that these phorid flies must use other shorter-range cues in addition to formic acid to locate their hosts [44].

Three species of Pseudacteon phorid flies [45] use compounds from the pygidial gland of their host Azteca instabilis as long-range host location cues. The pygidial gland of $A$. instabilis is the source of the alarm pheromone. At least one compound present within the pygidial gland of A. instabilis, 1-acetyl-2-methylcyclopentane, attracts one or more of these phorid fly species to their host $[17,39]$, but further research is necessary to determine if all three phorid species are attracted to the same compound or suite of compounds.

The Solenopsis saevissima complex has one of the largest groups of congeneric parasitoids recorded, with more than 18 Pseudacteon spp. known to parasitize this host group. However, despite significant research on these interactions, the details of the host location cues used in these interactions have remained somewhat elusive. In an early study, several of these phorids were categorized based on whether they were more likely to be found near disturbed ant mounds or trails - with the general hypothesis that phorid flies attacking ants near disturbed mounds must use alarm or defense compounds released by the ants as host location cues, and trail pheromone as a cue if they attack near trails. Pseudacteon litoralis, $P$. tricuspis, and P. wasmanni were all found attacking predominately near disturbed mounds or, in a few circumstances, trails where aggressive interspecies interactions were taking place between the ants. Pseudacteon obtusus, Pseudacteon borgmeieri, Pseudacteon nuicornis, and Pseudacteon solenopsidis were more often found attacking ants on trails $[20,46]$. In another set of studies, $P$. tricuspis was attracted to the midden (consisting primarily of dead workers) of Solenopsis invicta, lending further evidence to the hypothesis that its host location cue is a volatile chemical from the ants themselves [47, 48]. Additionally shaken workers both elicit an alarm response in other workers and attract phorid flies [49]. Electroantennogram (EAG) experiments with $P$. tricuspis show that the flies are attracted to whole body extracts of workers, ant heads (including, to some extent, the mandible alone), and abdomens [49]. The same study confirmed that $P$. tricuspis is not attracted to the trail pheromone of Solenopsis invicta, (E,E)- $\alpha$-farnesene [49]. The mandibular glands located within the head of Solenopsis spp. ants are the source of the ant's alarm pheromone, providing evidence that $P$. tricuspis likely uses a set of (rather than an individual) alarm pheromone compounds as a host location cue $[50,51]$. Recently, 2-ethyl-3,6-dimethylpyrazine has been confirmed as an active alarm pheromone component from within the 
mandibular glands of $S$. invicta and EAG experiments shows that this compound elicits a response in P. tricuspis, though the compound has yet to be tested in the field [40, 41].

Yet, not all ant-phorid relationships appear to involve long-range chemical cues. In behavioral observations of $N$. elongata phorid flies and $A$. sexdens ants using a $50 \mathrm{~cm}^{3}$ observation chamber, Gazal et al. (2009) concluded that these phorids do not have a volatile chemical cue involved in host location [18]. However, it is possible that these cues are essential when phorids are at a greater distance from potential hosts and behavioral observations of ants and phorids in small and contained areas underestimate phorid specificity [52].

\section{Host Acceptance}

Short-range cues used by phorid flies to inspect potential hosts and determine whether they are suitable for oviposition can be visual or chemical or in some cases both (Table 2). Visual cues are often multifaceted, including several simultaneous or sequential features such as movement, host size, and host shape. The chemical cues used in host acceptance are generally less volatile compounds that can only be detectable at close range.

Movement of target ants is a common visual cue frequently used by the Pseudacteon spp. phorid flies that attack both $A$. instabilis and ants in the Solenopsis saevissima complex as well as by $N$. elongata phorid flies attacking $A$. sexdens [16-19]. A. paraponerae attacking $P$. clavata, however, prefer stationary ant hosts [5].

Size is also an important factor in phorid host acceptance. Variation in size preferences between phorid species attacking the same host is generally seen as an effective method of niche partitioning $[16,20,22,25]$. Within the guild of phorids that attack the Solenopsis saevissima complex, $P$. curvatus, P. nudicornis, and P. obtusus attack small workers, $P$. tricuspis and P. wasmanni prefer medium-sized workers, $P$. borgmeieri, and $P$. solenopsidis tend to attack medium to large workers, and $P$. litoralis attacks large workers [7, 16, 20-24]. Size of the phorid fly is to a great extent a function of host body size $[25,55]$. In the case of $P$. obtusus, the small and large biotypes that are otherwise morphologically identical proved to be genetically distinct enough to be different species likely due to a variation in host size preference [56]. Moreover, in $P$. litoralis and $P$. tricuspis, sex ratio is determined by the body size of the host, where larger host ants yield female offspring and smaller host ants yield male offspring [55]. Phorid flies in other genera also use size cues in host acceptance. $N$. elongata only attack $A$. sexdens foragers with a minimum head width of $1.6 \mathrm{~mm}$, and $A$. paraponerae prefer large $P$. clavata workers $[5,53]$.

The complexity of the visual stimulus related to shape has also been implicated in host acceptance. For example, $N$. elongata will inspect (i.e., hover over) moving visual stimulus of varying degrees of complexity from simple to complex: one model mass sphere, two linked spheres, three linked spheres, a plastic ant model, and the host ant. Yet, the phorids only attack the most complex visual stimulus, which in the experiments was the host ant. Indeed, in this set of experiments, movement was unnecessary to trigger inspection if the visual stimulus was identical to the host, indicating that movement may act as a secondary cue to shape or visual complexity cues in order to enhance the speed and accuracy of attacks in this species [18].

Two classes of short-range chemical cues have been identified in phorid-ant interactions, cuticular hydrocarbons and low volatility venom gland secretions. While $A$. paraponerae flies are equally attracted to untreated ants and ants treated with hexane to remove cuticular hydrocarbons, the flies significantly prefer to lay eggs in ants with cuticular hydrocarbons [5]. Recent work on three Pseudacteon spp. phorid flies [45] that attack A. instabilis ants also show that these phorid flies may use cuticular hydrocarbons in host acceptance. When cuticular hydrocarbons of other ant species were applied to live A. instabilis ants, these Pseudacteon spp. phorid flies were much less likely to attack the ants than $A$. instabilis ants that were coated in additional $A$. instabilis cuticular hydrocarbons [54]. In experiments using electroantennograms and y-tube olfactometer bioassays, $P$. tricuspis flies used venom gland secretions of S. invicta in host acceptance. These experiments show that several piperidine alkaloids, which are present in the ant's venom glands and used in defense, act as short-range attractants [26].

\section{Host Discrimination}

The ability for parasitoids to distinguish between unparasitized potential hosts and hosts that have been previously parasitized is evolutionarily favorable as offspring from the same species within a single host are at a competitive disadvantage [1]. In fact, many parasitic hymenoptera can distinguish between parasitized and unparasitized hosts. Hymenopteran parasitoids use a variety of inhibitory cues in host discrimination including internal and external hostmarking pheromones, or visual cues such as oviposition wounds [1].

In contrast, dipteran parasitoids, including phorid flies, appear to have high rates of superparasitism within populations [6]. For example, incidences of superparasitism by Neodohrniphora curvinervis on Atta cephalotes ants are relatively high at $19 \%$ in one field study [53]. Superparasitism by $N$. elongata on $A$. sexdens has been reported at $29.4 \%$ self-superparasitism and $49.5 \%$ conspecific superparasitism in a study conducted under lab conditions [57]. However, behavioral observations also show that once a $A$. sexdens host ant is parasitized, it is significantly less likely to be parasitized again by $N$. elongata, indicating that $N$. elongata are able to discriminate between parasitized and nonparasitized host ants but may in some circumstances (e.g., lab conditions) choose to superparasitize a host. Thus, it appears, however these $N$. elongata do have some, however imperfect, form of host discrimination, that despite the cues [57]. Dipteran parasitoids such as phorid flies do not have the accessory glands commonly used by hymenopteran parasitoids to produce host-marking pheromones $[6,58]$. Thus, while more work is needed to determine the mechanism, it seems most likely that at least some phorid flies use visual cues from the ants' oviposition wounds in host discrimination. 
TABLe 2: Host acceptance cues used by phorid flies to choose ant hosts.

\begin{tabular}{|c|c|c|c|c|c|c|}
\hline Cue modality & Phorid species & Ant species & Cue & Source & Ant use & Ref. \\
\hline \multirow{14}{*}{ Visual } & Pseudacteon spp. & $\begin{array}{l}\text { Solenopsis } \\
\text { saevissima } \\
\text { complex }\end{array}$ & Movement & - & - & {$[16,19]$} \\
\hline & Pseudacteon spp. & Azteca instabilis & Movement & - & - & {$[17]$} \\
\hline & $\begin{array}{c}\text { Neodohrniphora } \\
\text { elongata }\end{array}$ & Atta sexdens & Movement & - & - & {$[18]$} \\
\hline & $\begin{array}{l}\text { Apocephalus } \\
\text { paraponerae }\end{array}$ & $\begin{array}{l}\text { Paraponera } \\
\text { clavata }\end{array}$ & No movement & - & - & {$[5]$} \\
\hline & $\begin{array}{l}\text { Pseudacteon } \\
\text { nuicornis }\end{array}$ & $\begin{array}{l}\text { Solenopsis } \\
\text { saevissima } \\
\text { complex }\end{array}$ & $\begin{array}{l}\text { Small-sized } \\
\text { workers }\end{array}$ & - & - & {$[16]$} \\
\hline & $\begin{array}{c}\text { Pseudacteon } \\
\text { obtusus }\end{array}$ & $\begin{array}{l}\text { Solenopsis } \\
\text { saevissima } \\
\text { complex }\end{array}$ & $\begin{array}{l}\text { Small-sized } \\
\text { workers }\end{array}$ & - & - & {$[16]$} \\
\hline & $\begin{array}{l}\text { Pseudacteon } \\
\text { curvatus }\end{array}$ & $\begin{array}{l}\text { Solenopsis } \\
\text { saevissima } \\
\text { complex }\end{array}$ & $\begin{array}{l}\text { Small-sized } \\
\text { workers }\end{array}$ & - & - & {$[16]$} \\
\hline & $\begin{array}{l}\text { Pseudacteon } \\
\text { tricuspis }\end{array}$ & $\begin{array}{l}\text { Solenopsis } \\
\text { saevissima } \\
\text { complex }\end{array}$ & $\begin{array}{l}\text { Medium-sized } \\
\text { workers }\end{array}$ & - & - & {$[16]$} \\
\hline & $\begin{array}{l}\text { Pseudacteon } \\
\text { wasmanni }\end{array}$ & $\begin{array}{l}\text { Solenopsis } \\
\text { saevissima } \\
\text { complex }\end{array}$ & $\begin{array}{l}\text { Medium-sized } \\
\text { workers }\end{array}$ & - & - & {$[16]$} \\
\hline & $\begin{array}{c}\text { Pseudacteon } \\
\text { borgmeieri }\end{array}$ & $\begin{array}{l}\text { Solenopsis } \\
\text { saevissima } \\
\text { complex }\end{array}$ & $\begin{array}{l}\text { Medium- to } \\
\text { Larger-sized } \\
\text { workers }\end{array}$ & - & - & {$[16]$} \\
\hline & $\begin{array}{l}\text { Pseudacteon } \\
\text { solenopsidis }\end{array}$ & $\begin{array}{l}\text { Solenopsis } \\
\text { saevissima } \\
\text { complex }\end{array}$ & $\begin{array}{l}\text { Medium- to } \\
\text { Larger-sized } \\
\text { workers }\end{array}$ & - & - & {$[16]$} \\
\hline & $\begin{array}{l}\text { Pseudacteon } \\
\text { litoralis }\end{array}$ & $\begin{array}{l}\text { Solenopsis } \\
\text { saevissima } \\
\text { complex }\end{array}$ & $\begin{array}{l}\text { Larger-sized } \\
\text { workers }\end{array}$ & - & - & {$[16]$} \\
\hline & $\begin{array}{c}\text { Neodohrniphora } \\
\text { elongata }\end{array}$ & Atta sexdens & $\begin{array}{l}\text { Minimum head } \\
\text { width of } 1.6 \mathrm{~mm}\end{array}$ & - & - & {$[53]$} \\
\hline & $\begin{array}{l}\text { Apocephalus } \\
\text { paraponerae }\end{array}$ & $\begin{array}{l}\text { Paraponera } \\
\text { clavata }\end{array}$ & Large workers & - & - & {$[5]$} \\
\hline \multirow{3}{*}{ Chemical } & $\begin{array}{l}\text { Apocephalus } \\
\text { paraponerae }\end{array}$ & $\begin{array}{l}\text { Paraponera } \\
\text { clavata }\end{array}$ & $\begin{array}{c}\text { Cuticular } \\
\text { hydrocarbons }\end{array}$ & - & $\begin{array}{l}\text { Nest mate } \\
\text { recognition }\end{array}$ & {$[5]$} \\
\hline & Pseudacteon spp. & Azteca instabilis & $\begin{array}{c}\text { Cuticular } \\
\text { hydrocarbons }\end{array}$ & - & $\begin{array}{l}\text { Nest mate } \\
\text { recognition }\end{array}$ & {$[54]$} \\
\hline & $\begin{array}{l}\text { Pseudacteon } \\
\text { tricuspis }\end{array}$ & $\begin{array}{l}\text { Solenopsis } \\
\text { invicta }\end{array}$ & $\begin{array}{l}\text { Piperidine } \\
\text { alkaloids }\end{array}$ & Venom glands & $\begin{array}{c}\text { Defense } \\
\text { pheromone }\end{array}$ & {$[26]$} \\
\hline
\end{tabular}

In other ant-phorid fly relationships, superparasitism has only been observed in laboratory experiments where the phorid flies were relatively contained and the phorid fly to individual ant ratio was higher than what would commonly be seen in the field. In a study with Pseudacteon tricuspis and Solenopsis invicta, laboratory experiments showed the rate of superparasitism to be approximately $15.4 \%$; however, these results do not accurately reflect the rate of superparasitism under natural conditions [8]. Thus, more studies are needed to determine whether superparasitism occurs in the field and whether it is a density-dependent phenomenon potentially affected by colony size or ant behavior.

\section{Host Regulation}

While relatively little is known about how phorid flies, in general, may manipulate their host's physiology in order to optimize the development of their offspring, strides have been made to understand the role of host regulation of $S$. invicta by $P$. tricuspis phorid flies. Like many other dipteran parasitoids, the developing phorid flies build respiratory structures in order to access fresh air through a hole in the integument of the host ant's head capsule [8]. Additionally, developing $P$. tricuspis is suspected to affect the neurophysiology of its ant hosts, as parasitized ants have 
altered behavior whereby they remain safely within the nest until just before the phorid larvae decapitate their hosts. Shortly before decapitation, ants will leave the nest, presumably to find a suitable location for the phorid fly to continue pupation and emerge [59]. However, much remains unknown about the mechanisms by which these behavioral changes manifest in their host. Furthermore, there is nothing known about how any other phorid species are able to affect the behavior or growth of host ant species.

\section{Conclusions and Future Prospects}

In order to successfully parasitize a host, phorid fly parasitoids must undergo a multistep process to detect and interpret a wide range of cues from their ant hosts. These cocktails of cues, each of which may vary in degrees of host specificity and timing of detection (sequentially or simultaneously), allow the flies to find suitable hosts in a complex environment. Researchers often study the interactions between phorid flies and their ant hosts in order to address the role of phorid flies as potential biological control agents of ants $[30,46,60-66]$. However, understanding these interactions could potentially shed light on evolutionary and ecological processes as well as provide a better understanding of multimodal communication.

Cues used by phorid flies are often traits considered to be highly conserved within the host species. These conserved traits are highly reliable and thus adaptive to phorid flies. Yet, little is known about how phorid use of these cues impacts the adaptive nature of these traits within ants. For example, $P$. clavata was originally thought to have no alarm pheromone responses, as these ants are relatively primitive and therefore independent outside of the nests, not requiring the assistance of their sisters during foraging. However, some studies indicate that $P$. clavata does have fairly developed intraspecific interactions during foraging $[67,68]$. As previously mentioned, A. paraponerae use the alarm pheromones, 4-methyl-3-heptanol and 4-methyl-3-heptanone, to locate its hosts. Though more intensive investigation is required, it is possible that the use of alarm pheromone by P. clavata has been selected against in order to decrease parasitism. On evolutionary timescales, perhaps phorid use of chemical and visual cues has affected ant morphology, behavior, and chemical communication.

While phorid flies are ubiquitous and conspicuous users of ant cues, a wide variety of other organisms are attracted to ants $[69,70]$. Considering the context-dependent nature of successful parasitism discussed above, it seems likely that multiple myrmecophiles are utilizing similar cues and may thus affect the parasitism process. Indeed, only considering pair-wise interactions between organisms rather than interactions between a network of multiple parties with distinct cue preferences, perceptions, and responses can be misleading. For example, competitive interactions between male hermit crabs affect mating strategy decisions of how male hermit crabs approach females [71]. Additionally, antAcacia mutualisms are now better understood based on the overall fitness benefits to the Acacia plants via a network of ant species rather than summing the effects of individual ant species separately and, in coffee agroecosystems, the nuances of multiple insect-interactions give insight into the overall effects of coffee pests [72-75]. Thus, a network approach should be taken and future work should be conducted to elucidate how other ant symbionts may affect these phoridant interactions. Additionally, as phorid fly behavior is often dependent on a wide array of factors that may be altered in laboratory observations, more studies should be conducted in the field to verify the results of lab experiments.

Finally, phorid flies are often both ecologically relevant species and have remarkably diverse strategies for using diverse arrays of multimodal cues within a complex environment to successfully parasitize host ants $[5,17,18,26,30,39$, 41]. Thus, phorid-ant interactions are ideal systems to bridge the gap between model organisms used in integrated pest management and model organisms used in understanding the behavioral ecology of multimodal cue use.

\section{Acknowledgments}

This work was supported by NSF Grant DEB no. 1020096 to Stacy M. Philpott, NSF Grant DGE no. 110640 to Kaitlyn A. Mathis and by the Graduate Division of the University of California, Berkeley.

\section{References}

[1] S. B. Vinson, "Host selection by insect parasitoids," Annual Review of Entomology, vol. 21, pp. 109-133, 1976.

[2] B. V. Brown and D. H. Feener, "Behavior and host location cues of Apocephalus paraponerae (Diptera: Phoridae), a parasitoid of the giant tropical ant, Paraponera clavata (Hymenoptera: Formicidae)," Biotropica, vol. 23, no. 2, pp. 182-187, 1991.

[3] R. H. L. Disney, Scuttle Flies: The Phoridae, Chapman \& Hall, London, UK, 1994.

[4] D. H. Feener, L. F. Jacobs, and J. O. Schmidt, "Specialized parasitoid attracted to a pheromone of ants," Animal Behaviour, vol. 51, no. 1, pp. 61-66, 1996.

[5] S. A. Morehead and D. H. Feener, "Visual and chemical cues used in host location and acceptance by a Dipteran parasitoid," Journal of Insect Behavior, vol. 13, no. 4, pp. 613-625, 2000.

[6] D. H. Feener and B. V. Brown, "Diptera as parasitoids," Annual Review of Entomology, vol. 42, pp. 73-97, 1997.

[7] S. D. Porter, "Biology and behavior of Pseudacteon decapitating flies (Diptera: Phoridae) that parasitize Solenopsis fire ants (Hymenoptera: Formicidae)," The Florida Entomologist, vol. 81, no. 3, pp. 292-309, 1998.

[8] F. L. Cônsoli, C. T. Wuellner, S. B. Vinson, and L. E. Gilbert, "Immature development of Pseudacteon tricuspis (Diptera : Phoridae), an endoparasitoid of the red imported fire ant (Hymenoptera: Formicidae)," Annals of the Entomological Society of America, vol. 94, no. 1, pp. 97-109, 2001.

[9] D. H. Feener, "Competition between ant species: outcome controlled by parasitic flies," Science, vol. 214, no. 4522, pp. 815-817, 1981.

[10] D. H. Feener and B. V. Brown, "Reduced foraging of Solenopsis geminata (Hymenoptera, Formicidae) in the presence of parasitic Pseudacteon spp. (Diptera, Phoridae)," Annals of the Entomological Society of America, vol. 85, no. 1, pp. 80-84, 1992. 
[11] M. R. Orr, S. H. Seike, W. W. Benson, and L. E. Gilbert, "Flies suppress fire ants," Nature, vol. 373, no. 6512, pp. 292-293, 1995.

[12] M. R. Orr, R. X. De Camargo, and W. W. Benson, "Interactions between ant species increase arrival rates of an ant parasitoid," Animal Behaviour, vol. 65, no. 6, pp. 1187-1193, 2003.

[13] J. Vandermeer, I. Perfecto, G. Ibarra Nuñez, S. Phillpott, and A. Garcia Ballinas, "Ants (Azteca sp.) as potential biological control agents in shade coffee production in Chiapas, Mexico," Agroforestry Systems, vol. 56, no. 3, pp. 271-276, 2002.

[14] S. M. Philpott, "Trait-mediated effects of parasitic phorid flies (Diptera: Phoridae) on ant (Hymenoptera: Formicidae) competition and resource access in coffee agro-ecosystems," Environmental Entomology, vol. 34, no. 5, pp. 1089-1094, 2005.

[15] L. E. M. Vet and D. R. Papaj, "Effects of experience on parasitoid movement in odour plumes," Physiological Entomology, vol. 17, no. 1, pp. 90-96, 1992.

[16] C. T. Wuellner, C. G. Dall'Aglio-Holvorcem, W. W. Benson, and L. E. Gilbert, "Phorid fly (Diptera: Phoridae) oviposition behavior and fire ant (Hymenoptera: Formicidae) reaction to attack differ according to phorid species," Annals of the Entomological Society of America, vol. 95, no. 2, pp. 257-266, 2002.

[17] K. A. Mathis, S. M. Philpott, and R. F. Moreira, "Parasite lost: chemical and visual cues used by Pseudacteon in search of Azteca instabilis," Journal of Insect Behavior, vol. 24, no. 3, pp. 186-199, 2010.

[18] V. Gazal, O. Bailez, and A. M. Viana-Bailez, "Mechanism of host recognition in Neodohrniphora elongata (Brown) (Diptera: Phoridae)," Animal Behaviour, vol. 78, no. 5, pp. 1177-1182, 2009.

[19] V. S. G. Silva, O. Bailez, A. M. Viana-Bailez, A. Tonhasca, and T. M. Castro Della Lucia, "Survey of Neodohrniphora spp. (Diptera: Phoridae) at colonies of Atta sexdens rubropilosa (FOREL) and specificity of attack behaviour in relation to their hosts," Bulletin of Entomological Research, vol. 98, no. 2, pp. 203-206, 2008.

[20] M. R. Orr, S. H. Seike, and L. E. Gilbert, "Foraging ecology and patterns of diversification in dipteran parasitoids of fire ants in south Brazil," Ecological Entomology, vol. 22, no. 3, pp. 305-314, 1997.

[21] L. E. Gilbert and L. W. Morrison, "Patterns of host specificity in Pseudacteon parasitoid flies (Diptera: Phoridae) that attack Solenopsis fire ants (Hymenoptera: Formicidae)," Environmental Entomology, vol. 26, no. 5, pp. 1149-1154, 1997.

[22] L. W. Morrison, C. G. Dall'aglio-Holvorcem, and L. E. Gilbert, "Oviposition behavior and development of Pseudacteon flies (Diptera: Phoridae), parasitoids of Solenopsis fire ants (Hymenoptera: Formicidae)," Environmental Entomology, vol. 26, no. 3, pp. 716-724, 1997.

[23] M. A. Pesquero, S. Campiolo, H. G. Fowler, and S. D. Porter, "Diurnal patterns of ovipositional activity in two Pseudacteon fly parasitoids (Diptera: Phoridae) of Solenopsis fire ants (Hymenoptera: Formicidae)," The Florida Entomologist, vol. 79, no. 3, pp. 455-457, 1996.

[24] S. D. Porter, H. G. Fowler, S. Campiolo, and M. A. Pesquero, "Host specificity of several Pseudacteon (Diptera: Phoridae) parasites of fire ants (Hymenoptera: Formicidae) in South America," The Florida Entomologist, vol. 78, no. 1, pp. 70-75, 1995.

[25] L. W. Morrison and L. E. Gilbert, "Parasitoid-host relationships when host size varies: the case of Pseudacteon flies and Solenopsis fire ants," Ecological Entomology, vol. 23, no. 4, pp. 409-416, 1998.
[26] L. Chen, K. R. Sharma, and H. Y. Fadamiro, "Fire ant venom alkaloids act as key attractants for the parasitic phorid fly, Pseudacteon tricuspis (Diptera: Phoridae)," Naturwissenschaften, vol. 96, no. 12, pp. 1421-1429, 2009.

[27] M. A. L. Bragança, L. M. de Souza, C. A. Nogueira, and T. M.C. Della Lucia, "Parasitism by Neodohrniphora spp. Malloch (Diptera, Phoridae) on workers of Atta sexdens ribropilosa Forel (Hymenoptera, Formicidae)," Revista Brasileira de Entomologia, vol. 52, no. 2, pp. 300-302, 2008.

[28] M. A. L. Bragança, L. M. de Souza, C. A. Nogueira, and T. M. C. Della Lucia, "Parasitism by Neodohrniphora spp. Malloch (Diptera, Phoridae) on workers of Atta sexdens rubropilosa Forel (Hymenoptera, Formicidae)," Revista Brasileira de Entomologia, vol. 52, no. 2, pp. 300-302, 2008.

[29] L. G. Thead and D. A. Streett, "Confinement-tray background color affects parasitism rates of attacking Pseudacteon curvatus (Diptera: Phoridae) in a laboratory rearing system," Journal of Entomological Science, vol. 40, no. 3, pp. 263-267, 2005.

[30] P. J. Folgarait, O. A. Bruzzone, and L. E. Gilbert, "Seasonal patterns of activity among species of black fire ant parasitoid flies (Pseudacteon: Phoridae) in Argentina explained by analysis of climatic variables," Biological Control, vol. 28, no. 3, pp. 368378, 2003.

[31] L. Chen, E. O. Onagbola, and H. Y. Fadamiro, "Effects of temperature, sugar availability, gender, mating, and size on the longevity of phorid fly Pseudacteon tricuspis (Diptera: Phoridae)," Environmental Entomology, vol. 34, no. 2, pp. 246-255, 2005.

[32] E. G. LeBrun, R. M. Plowes, and L. E. Gilbert, "Dynamic expansion in recently introduced populations of fire ant parasitoids (Diptera : Phoridae)," Biological Invasions, vol. 10, no. 7, pp. 989-999, 2008.

[33] E. B. Wilkinson and D. H. Feener, "Habitat complexity modifies ant-parasitoid interactions: implications for community dynamics and the role of disturbance," Oecologia, vol. 152, no. 1, pp. 151-161, 2007.

[34] G. L. Pardee and S. M. Philpott, "Cascading indirect effects in a coffee agroecosystem: effects of parasitic phorid flies on ants and the coffee berry borer in a high-shade and low-shade habitat," Environmental Entomology, vol. 40, no. 3, pp. 581-588, 2011.

[35] H. R. Hermann, M. S. Blum, J. W. Wheeler, W. L. Overal, J. O. Schmidt, and J. T. Chao, "Comparative anatomy and chemistry of the venom apparatus and mandibular glands in Dinoponera grandis (Guérin) and Paraponera clavata (F) (Hymenoptera-Formicinae-Ponerinae)," Annals of the Entomological Society of America, vol. 77, no. 3, pp. 272-289, 1984.

[36] V. Witte, R. H. L. Disney, A. Weissflog, and U. Maschwitz, "Studies in European ant-decapitating flies (Diptera: Phoridae): ant alarm pheromone as host finding cue in Pseudacteon brevicauda, a parasite of Myrmica rubra (Formicidae: Myrmicinae)," Journal of Natural History, vol. 44, no. 15-16, pp. 905-912, 2010.

[37] M. C. Cammaerts, R. P. Evershed, and E. D. Morgan, "Comparative study of the dufour gland secretions of workers of four species of Myrmica ants," Journal of Insect Physiology, vol. 27, no. 1, pp. 59-65, 1981.

[38] U. Maschwitz, A. Weissflog, S. Seebauer, R. H. L. Disney, and V. Witte, "Studies on European ant decapitating flies (Diptera: Phoridae): I. Releasers and phenology of parasitism of Pseudacteon formicarum," Sociobiology, vol. 51, no. 1, pp. 127-140, 2008.

[39] J. W. Wheeler, S. L. Evans, M. S. Blum, and R. L. Torgerson, "Cyclopentyl ketones: identification and function in Azteca ants," Science, vol. 187, no. 4173, pp. 254-255, 1975. 
[40] R. K. Vander Meer, C. A. Preston, and M. Y. Choi, "solation of a pyrazine alarm pheromone component from the fire ant, Solenopsis invicta," Journal of Chemical Ecology, vol. 36, no. 2, pp. 163-170, 2010.

[41] K. Sharma, R. K. Vander Meer, and H. Y. Fadamiro, "Phorid fly, Pseudacteon tricuspis, response to alkylpyrazine analogs of a fire ant, Solenopsis invicta, alarm pheromone," Journal of Insect Physiology, vol. 57, no. 7, pp. 939-944, 2011.

[42] S. D. Porter, "Host-specific attraction of Pseudacteon flies (Diptera: Phoridae) to fire ant colonies in Brazil," The Florida Entomologist, vol. 81, no. 3, pp. 423-429, 1998.

[43] M. Zuk and G. R. Kolluru, "Exploitation of sexual signals by predators and parasitoids," The Quarterly Review of Biology, vol. 73, no. 4, pp. 415-438, 1998.

[44] A. Weissflog, U. Maschwitz, S. Seebauer, R. H. L. Disney, B. Seifert, and V. Witte, "Studies on European ant decapitating flies (Diptera: Phoridae): II. Observations that contradict the reported catholicity of host choice by Pseudacteon formicarum," Sociobiology, vol. 51, no. 1, pp. 87-94, 2008.

[45] B. V. Brown and S. M. Philpott, "Phorid parasitoids of Azteca ants in Central America (Diptera: Phoridae, Hymenoptera: Formicidae)," in preparation.

[46] L. W. Morrison and J. R. King, "Host location behavior in a parasitoid of imported fire ants," Journal of Insect Behavior, vol. 17, no. 3, pp. 367-383, 2004.

[47] L. E. Gilbert and R. J. W. Patrock, "Phorid flies for the biological suppression of imported fire ant in Texas: region specific challenges, recent advances and future prospects," Southwestern Entomologist, vol. 25, supplement, pp. 7-17, 2002.

[48] R. T. Puckett, A. Calixto, C. L. Barr, and M. Harris, "Sticky traps for monitoring Pseudacteon parasitoids of Solenopsis fire ants," Environmental Entomology, vol. 36, no. 3, pp. 584-588, 2007.

[49] R. K. Vander Meer, T. J. Slowik, and H. G. Thorvilson, "Semiochemicals released by electrically stimulated red imported fire ants, Solenopsis invicta," Journal of Chemical Ecology, vol. 28, no. 12, pp. 2585-2600, 2002.

[50] R. K. Vander Meer, "Potential role of pheromones in fire ant control," in Pest Management in the Subtropics: Integrated Pest Management: A Florida Perspective, D. Rosen, F. D. Bennet, and J. L. Capinera, Eds., pp. 223-232, Intercept Ltd., Andover, UK, 1996.

[51] R. K. Vander Meer and L. E. Alonso, "Pheromone directed behavior in ants," in Pheromone Communication in Social Insects: Ants, Wasps, Bees and Termites, R. K. Vander Meer, M. D. Breed, K. E. Espelie, and M. L. Winston, Eds., pp. 159-192, Westview Press, Boulder, Colo, USA, 1998.

[52] M. R. Orr, S. H. Seike, W. W. Benson, and D. L. Dahlsten, "Host specificity of Pseudacteon (Diptera: Phoridae) parasitoids that attack Linepithema (Hymenoptera: Formicidae) in South America," Environmental Entomology, vol. 30, no. 4, pp. 742-747, 2001.

[53] D. H. Feener Jnr and B. V. Brown, "Oviposition behavior of an ant-parasitizing fly, Neodohrniphora curvinervis (Diptera: Phoridae), and defense behavior by its leaf-cutting ant host Atta cephalotes (Hymenoptera: Formicidae)," Journal of Insect Behavior, vol. 6, no. 6, pp. 675-688, 1993.

[54] K. A. Mathis and N. Tsutsui, "Cuticular hydrocarbon cues used in host acceptance by Pseudacteon spp. phorid flies that attack Azteca instabilis ants," in preparation.

[55] L. W. Morrison, S. D. Porter, and L. E. Gilbert, "Sex ratio variation as a function of host size in Pseudacteon flies (Diptera: Phoridae), parasitoids of Solenopsis fire ants (Hymenoptera: Formicidae)," Biological Journal of the Linnean Society, vol. 66, no. 2, pp. 257-267, 1999.
[56] M. R. Kronforst, P. J. Folgarait, R. J. W. Patrock, and L. E. Gilbert, "Genetic differentiation between body size biotypes of the parasitoid fly Pseudacteon obtusus (Diptera: Phoridae)," Molecular Phylogenetics and Evolution, vol. 43, no. 3, pp. 11781184, 2007.

[57] M. A. L. Bragança, C. A. Nogueira, L. M. Souza, and T. M. C. Delia Lucia, "Superparasitism and host discrimination by Neodohrniphora elongata (Diptera: Phoridae), a parasitoid of the leaf-cutting ant Atta sexdens rubropilosa (Hymenoptera: Formicidae)," Sociobiology, vol. 54, no. 3, pp. 907-918, 2009.

[58] M. L. Dindo, "Tachinid parasitoids: are they to be considered as koinobionts?" BioControl, pp. 1-7, 2010.

[59] D. C. Henne and S. J. Johnson, "Zombie fire ant workers: behavior controlled by decapitating fly parasitoids," Insectes Sociaux, vol. 54, no. 2, pp. 150-153, 2007.

[60] C. Estrada, R. J. W. Patrock, P. J. Folgarait, and L. E. Gilbert, "Host specificity of four Pseudacteon spp. (Diptera: Phoridae), parasitoids of fire ants in Argentina (Hymenoptera: Formicidae)," The Florida Entomologist, vol. 89, no. 4, pp. 462468, 2006.

[61] P. J. Folgarait, O. Bruzzone, S. D. Porter, M. A. Pesquero, and L. E. Gilbert, "Biogeography and macroecology of phorid flies that attack fire ants in south-eastern Brazil and Argentina," Journal of Biogeography, vol. 32, no. 2, pp. 353-367, 2005.

[62] S. D. Porter and J. A. Briano, "Parasitoid-host matching between the little decapitating fly Pseudacteon curvatus from Las Flores, Argentina and the black fire ant Solenopsis richteri," The Florida Entomologist, vol. 83, no. 4, pp. 422-427, 2000.

[63] M. A. L. Braganca, A. Tonhasca, and D. D. O. Moreira, "Parasitism characteristics of two phorid fly species in relation to their host, the leaf-cutting ant Atta laevigata (Smith) (hymenoptera: formicidae)," Neotropical Entomology, vol. 31, no. 2, pp. 241-244, 2002.

[64] S. D. Porter and L. E. Gilbert, "Assessing host specificity and field release potential of fire ant decapitating flies (Phoridae: Pseudacteon)," in Assessing Host Ranges of Parasitoids and Predators Used for Classical Biological Control: A Guide to Best Practice, R. G. Van Driesche and R. Reardon, Eds., pp. 152176, Forest Health Technology Enterprise Team, Morgantown, WVa, USA, 2004.

[65] S. D. Porter and L. E. Gilbert, "Parasitoid case history: an evaluation of methods used to assess host ranges of fire ant decapitating flies," in Proceedings of the 2nd International Symposium on Biological Control of Arthropods, pp. 634650, United States Department of Agriculture, Forest Service, Washington, DC, USA, 2005.

[66] R. G. Van Driesche and T. J. Murray, "Parameters used in laboratory host range tests," in Assessing Host Ranges for Parasitoids and Predators Used for Classical Biological Control: A Guide to Best Practice, R. G. Van Driesche and R. Reardon, Eds., pp. 56-67, Forest Health Technology Enterprise Team, Morgantown, WVa, USA, 2004.

[67] M. D. Breed, J. H. Fewell, A. J. Moore, and K. R. Williams, "Graded recruitment in a ponerine ant," Behavioral Ecology and Sociobiology, vol. 20, no. 6, pp. 407-411, 1987.

[68] J. H. Fewell, J. F. Harrison, T. M. Stiller, and M. D. Breed, "Distance effects on resource profitability and recruitment in the giant tropical ant, Paraponera clavata," Oecologia, vol. 92, no. 4 , pp. $542-547,1992$.

[69] C. W. Rettenmeyer, M. E. Rettenmeyer, J. Joseph, and S. M. Berghoff, "The largest animal association centered on one species: the army ant Eciton burchellii and its more than 300 associates," Insectes Sociaux, vol. 58, no. 3, pp. 281-292, 2010.

[70] B. Hölldobler and E. O. Wilson, The Ants, Harvard University Press, Cambridge, Mass, USA, 1990. 
[71] S. Wada, Y. Arashiro, F. Takeshita, and Y. Shibata, "Male mate choice in hermit crabs: prudence by inferior males and simple preference by superior males," Behavioral Ecology, vol. 22, no. 1, pp. 114-119, 2011.

[72] I. Perfecto and J. Vandermeer, "The effect of an anthemipteran mutualism on the coffee berry borer (Hypothenemus hampei) in southern Mexico," Agriculture, Ecosystems and Environment, vol. 117, no. 2-3, pp. 218-221, 2006.

[73] H. Liere and A. Larsen, "Cascading trait-mediation: disruption of a trait-mediated mutualism by parasite-induced behavioral modification," Oikos, vol. 119, no. 9, pp. 1394-1400, 2010.

[74] T. M. Palmer, D. F. Doak, M. L. Stanton et al., "Synergy of multiple partners, including freeloaders, increases host fitness in a multispecies mutualism," Proceedings of the National Academy of Sciences of the United States of America, vol. 107, no. 40, pp. 17234-17239, 2010.

[75] J. Vandermeer, I. Perfecto, and S. Philpott, "Ecological complexity and pest control in organic coffee production: uncovering an autonomous ecosystem service," BioScience, vol. 60, no. 7, pp. 527-537, 2010. 

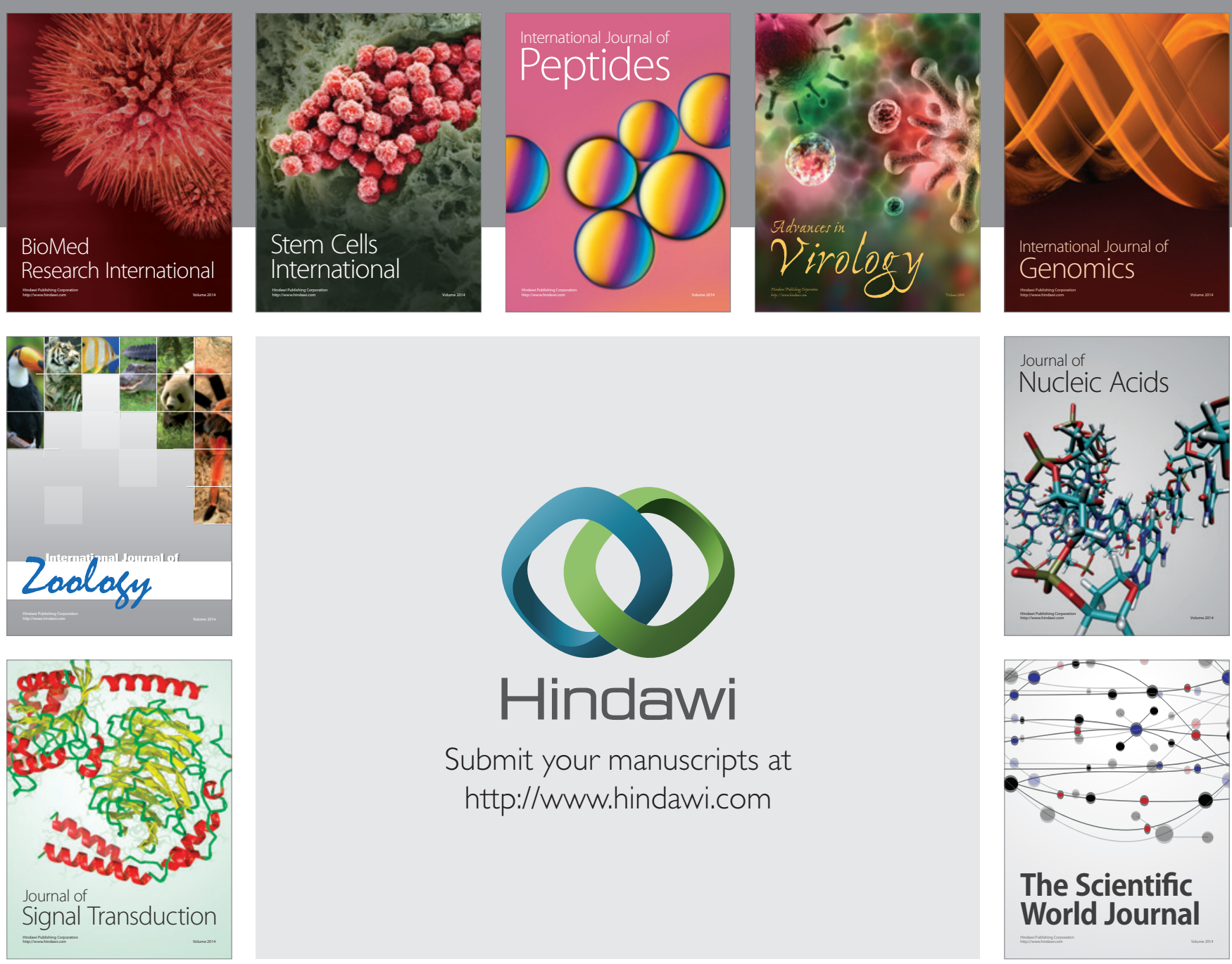

Submit your manuscripts at

http://www.hindawi.com
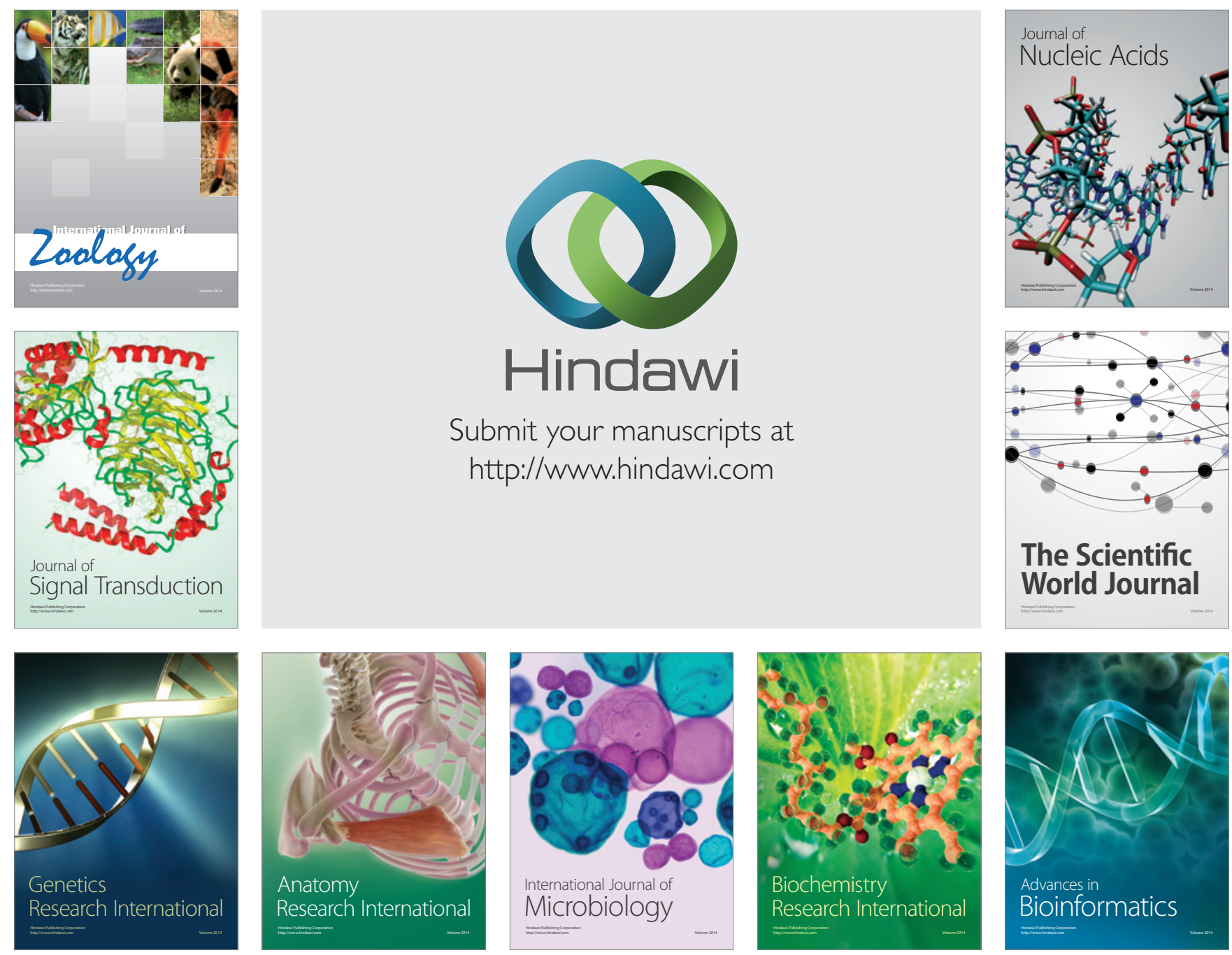

The Scientific World Journal
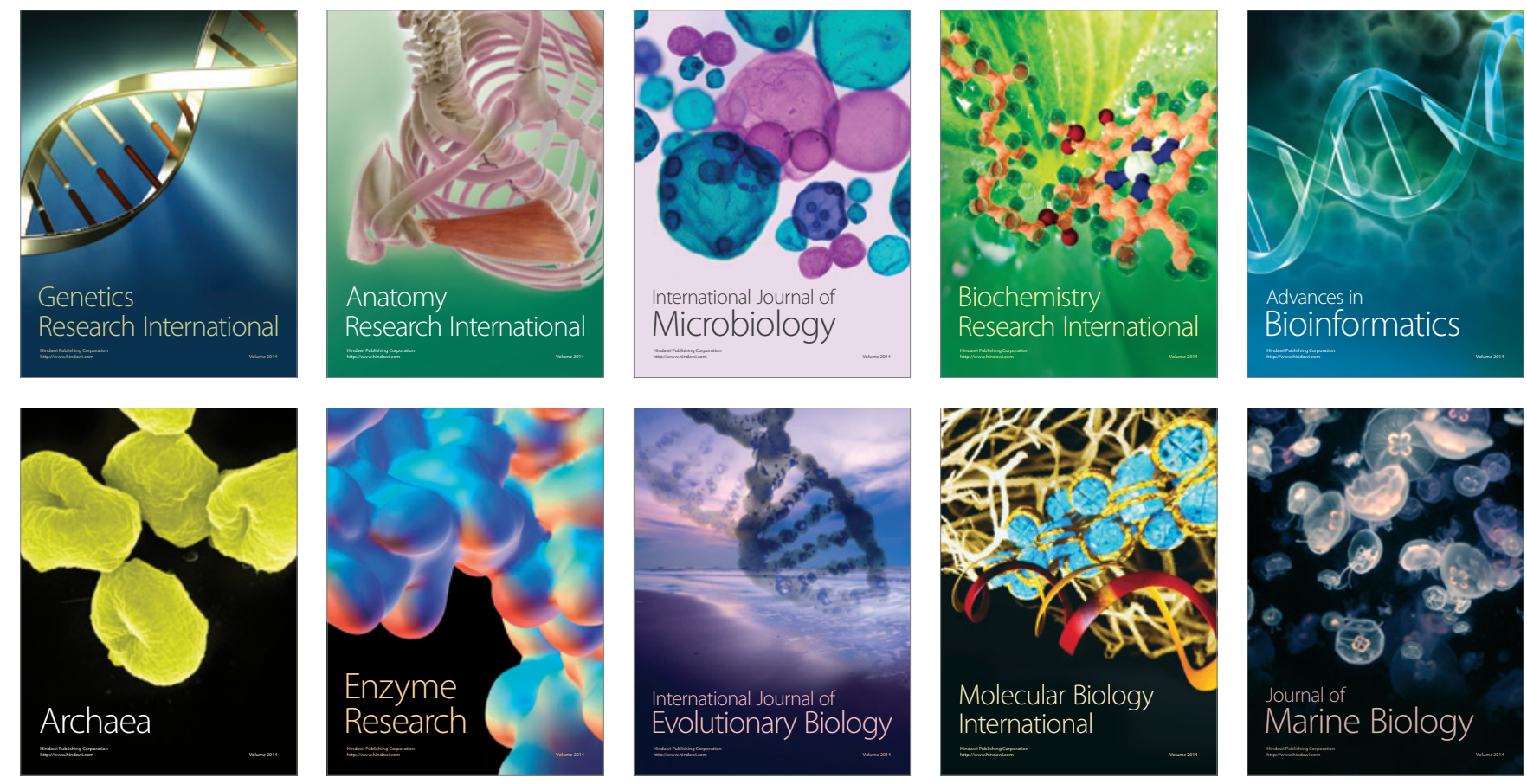